\title{
Precipitation Anomalies in Southern Brazil Associated with El Niño and La Niña Events
}

\author{
Alice M. GRIMM \\ Department of Physics, Federal University of Paraná, Curitiba, Parana, Brazil \\ SimONE E. T. FERRAZ \\ Program of Research Fellowships CNPq-UFPR, Parana, Brazil \\ JÚLIO GOMES \\ Simepar, Parana, Brazil
}

(Manuscript received 3 March 1997, in final form 19 November 1997)

\begin{abstract}
The impact of El Niño and La Niña events (warm and cold phases of the Southern Oscillation) on rainfall over southern Brazil is investigated through the use of a large dataset of monthly precipitation from 250 stations. This region is partly dominated by rough orography and presents different climatic regimes of rainfall. As previous global studies on Southern Oscillation-precipitation relationships used data from only two stations in southern Brazil, this region was not included in the area of consistent Southern Oscillation-related precipitation in southeastern South America. The present analysis is based on the method by Ropelewski and Halpert, the sensitivity of which is assessed for this region. The spatial structure of the rainfall anomalies associated with warm (cold) events is analyzed and subregions with coherent anomalies are determined. Their distribution indicates the influence of relief, latitude, and proximity to the ocean. These areas are subjected to further analysis to determine the seasons of largest anomalies and assess their consistency during warm (cold) events.

The whole of southern Brazil was found to have strong and consistent precipitation anomalies associated with those events. Their magnitude is even larger than in Argentina and Uruguay. All of the subregions have consistent wet anomalies during the austral spring of the warm event year, with a pronounced peak in November. The southeastern part also shows a consistent tendency to higher than average rainfall during the austral winter of the following year. There is also a consistent tendency to dryness in the year before a warm event. During the spring of cold event years strong consistent dry anomalies prevail over the whole region, also with maximum magnitude in November. They are even stronger and more consistent than the wet anomalies in warm event years. Consistent anomalies do not occur over large areas in the years before and after cold events. The wet anomalies during the austral spring of the warm event year weaken and even reverse during the following January. The same tendency, though not so clear, is observable in the dry anomalies of cold events. The seasons of largest anomalies disclosed by this study differ from those found by previous global studies for other regions in southeastern South America.

This study expands the area of consistent warm (cold) event-related precipitation defined by previous studies in southeastern South America by including a region of larger anomalies, and provides a spatial and temporal refinement to the warm (cold) event-precipitation relationship.
\end{abstract}

\section{Introduction}

According to studies of the global precipitation anomalies associated with the Southern Oscillation (SO), there is a region in southeastern South America (SSA) with a very consistent relationship between precipitation anomalies and extremes of the SO (e.g., Ropelewski

Corresponding author address: Dr. Alice M. Grimm, Department of Physics, Federal University of Paraná, Caixa Postal 19081, CEP 80531-990 Curitiba, Brazil.

E-mail: grimm@fisica.ufpr.br and Halpert 1987, 1989, hereafter RH87 and RH89; Kiladis and Diaz 1989). According to RH87, this region includes northeastern Argentina and Uruguay (Fig. 1). From composites of rainfall anomalies during several El Niño-Southern Oscillation episodes (ENSO, or warm phase of the $\mathrm{SO}$ ) they concluded that in this area rainfall anomalies are consistently positive from November of the ENSO year (year 0) to February of the next year $($ year + ). RH89 found that during the cold phase of the SO rainfall anomalies in this region are consistently negative for the June (0) to December (0) season. Those studies include only two stations in southern Brazil, which are not situated in the region defined by RH87. 


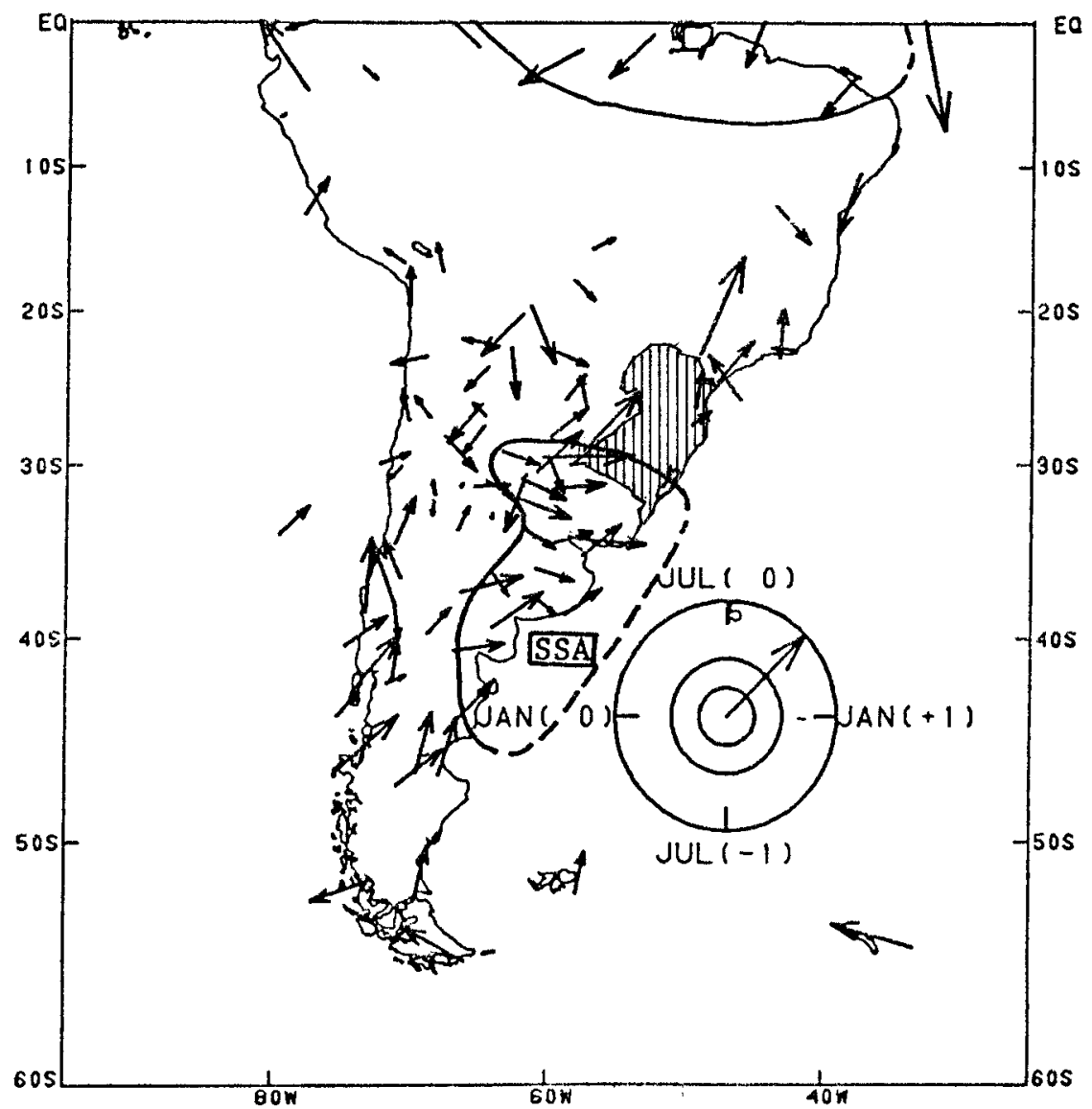

FIG. 1. Subjectively determined "core region" of consistent ENSO-related precipitation in southeastern South America, after Ropelewski and Halpert (1987). The hatched region is southern Brazil.

Therefore, the extension of their conclusions to southern Brazil is hampered by the shortage of data.

There are no comprehensive studies, supported by adequate datasets, of the effects of El Niño and La Niña events on southern Brazil, which comprises the states of Rio Grande do Sul, Santa Catarina, and Paraná. These effects extend over the whole region and not only the southernmost part, near the region defined by RH87, and the periods of maximum anomalies do not coincide with those of RH87. This suggests the existence of subregional differences in the impact of those events on rainfall over SSA and indicates the need for a specific study of that impact on southern Brazil. Subregional differences are also suggested by the low coherence found by RH87 for the region of consistent ENSO-related precipitation in SSA.
As southern Brazil is densely populated and concentrates great economic activity, modern agriculture, and intense generation of hydroelectric power, the floods and droughts associated with those episodes have had significant social and economic consequences. Therefore, the long-range forecasting of the seasonal precipitation anomalies associated with El Niño and La Niña is of great interest. Important steps toward this end are the knowledge of the spatial distribution of these anomalies, their magnitude, and their timings within an "average cycle" of these episodes, besides the verification of their consistency. These are the main objectives of this paper. This knowledge allows the linkage between the precipitation anomalies, the normal annual precipitation cycle, and the circulation features associated with El Niño and La Niña episodes, which is also discussed.

TAble 1. El Niño and La Niña events included in this study.

\begin{tabular}{ll}
\hline \hline El Niño years & $1911,1913,1915,1918,1923,1925,1930,1932,1939,1941,1944,1951,1953$, \\
& $1957,1963,1965,1969,1972,1976,1979,1982,1986,1991$. \\
La Niña years & $1910,1916,1917,1920,1924,1928,1931,1933,1938,1942,1949,1950,1954$, \\
& $1955,1956,1964,1970,1971,1973,1975,1985,1988$.
\end{tabular}




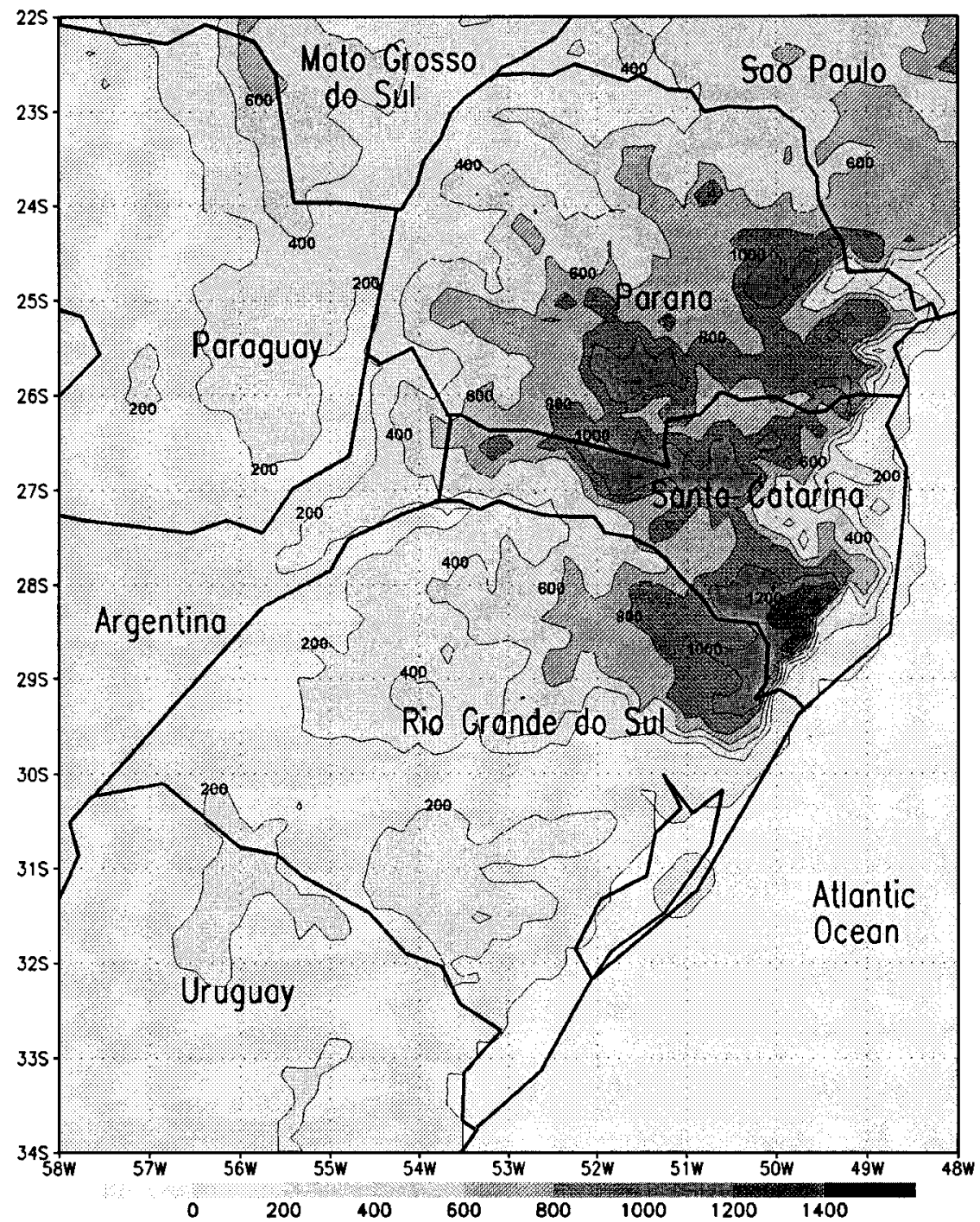

FIG. 2. Contours of surface elevation (m) above mean sea level in southern Brazil.

Differently from RH89, this study does not assume that the regions with coherent rainfall anomalies for the El Niño episodes will also be coherent with respect to La Niña-related precipitation. Therefore, the whole analysis applied to El Niño events is repeated for La Niña events.

Section 2 describes the data and features of the relief and the climatic regimes of precipitation of southern Brazil. Section 3 outlines the methodology for analysis, and in section 4 questions related to this methodology are discussed. The results are presented in section 5 and discussed in section 6 .

\section{Data and climatic aspects}

\section{a. Precipitation data}

The monthly precipitation amounts used in this study are extracted from daily station data obtained from the
Agência Nacional de Energia Elétrica, Instituto Nacional de Meteorologia, and other institutions from Paraná and Santa Catarina (Superintendência de Desenvolvimento de Recursos Hídricos e Saneamento Ambiental do Paraná, Companhia Paranaense de Energia Eléctrica, and Empresa de Pesquisa Agropecuária e Difusão de Tecnologia de Santa Catarina). We have selected 250 stations distributed all over southern Brazil, whose data span at least five warm (or cold) episodes. However, most of the data series include more than 10 episodes.

The dataset is initially submitted to an absolute method for detection of doubtful data. Missing monthly data, if not numerous, are estimated with the method of Tabony (1983). The estimation procedure uses data from neighbor stations whose correlation coefficient is significant, at a level better than $95 \%$, and performs an average of the linear regression estimates weighted by the correlation coefficients. A smoothing procedure, 


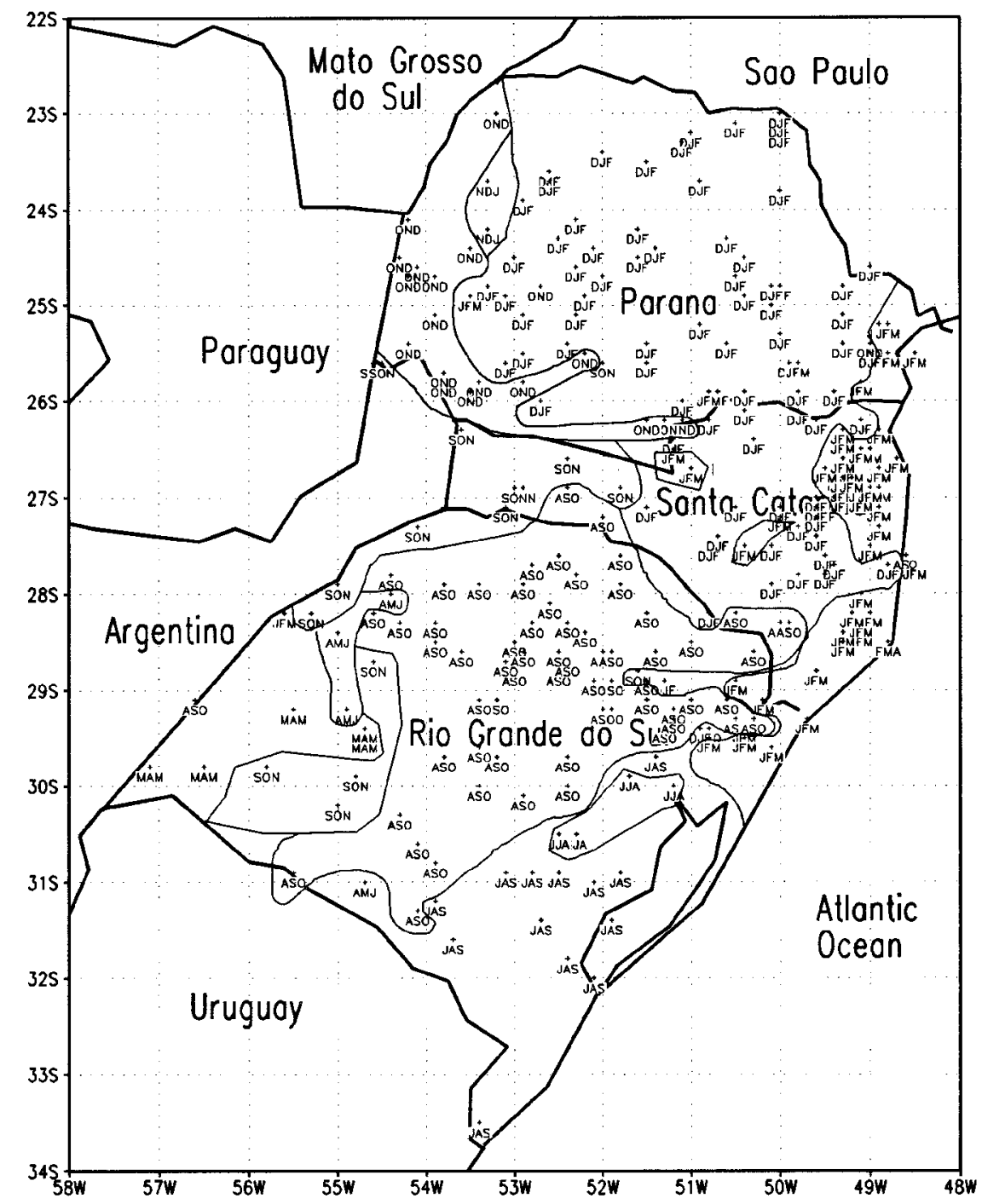

FIG. 3. Peak wet season in southern Brazil. The three letters are the initials of the three consecutive months having the highest rainfall.

TABLE 2. Values of the index of spatial coherence for subregions $\mathrm{A}, \mathrm{B}$, and $\mathrm{A}+\mathrm{B}$, obtained by using different periods for the composites.

\begin{tabular}{lcccc}
\hline \hline & $\begin{array}{c}\text { Number } \\
\text { of } \\
\text { Ponths }\end{array}$ & $\begin{array}{c}\text { Subregion } \\
\text { A }\end{array}$ & $\begin{array}{c}\text { Subregion } \\
\text { B }\end{array}$ & $\begin{array}{c}\text { Subregions } \\
\text { A + B }\end{array}$ \\
\hline Jul(-)-June(+) & 24 & 0.958 & 0.956 & 0.851 \\
Jan(-)-Dec(0) & 24 & 0.863 & 0.862 & 0.858 \\
Jan(0)-Dec(+) & 24 & 0.929 & 0.938 & 0.768 \\
Apr(-)-Sep(+) & 30 & 0.936 & 0.972 & 0.889 \\
Jan(-)-Jul(+) & 30 & 0.936 & 0.923 & 0.899 \\
Jul(-)-Dec(+) & 30 & 0.949 & 0.979 & 0.841 \\
Jan(-)-Dec(+) & 36 & 0.929 & 0.937 & 0.863 \\
\hline
\end{tabular}

which takes into account the regression parameters for the adjacent months, is also included.

\section{b. El Niño and La Niña events}

There is some disagreement among various authors as to which years were actually El Niño or La Niña years. Most investigators recognize strong events, but there are some differences in their lists of other episodes because of the different criteria they use in defining events. According to Trenberth (1996a) the statistical reliability of the influence of ENSO events at extratropical latitudes is poor, at least insofar as the events are stratified only as ENSO events without factoring in the different types of ENSO events. In order to see whether there is a consistent impact of El Niño and La Niña events on precipitation in southern Brazil regard- 


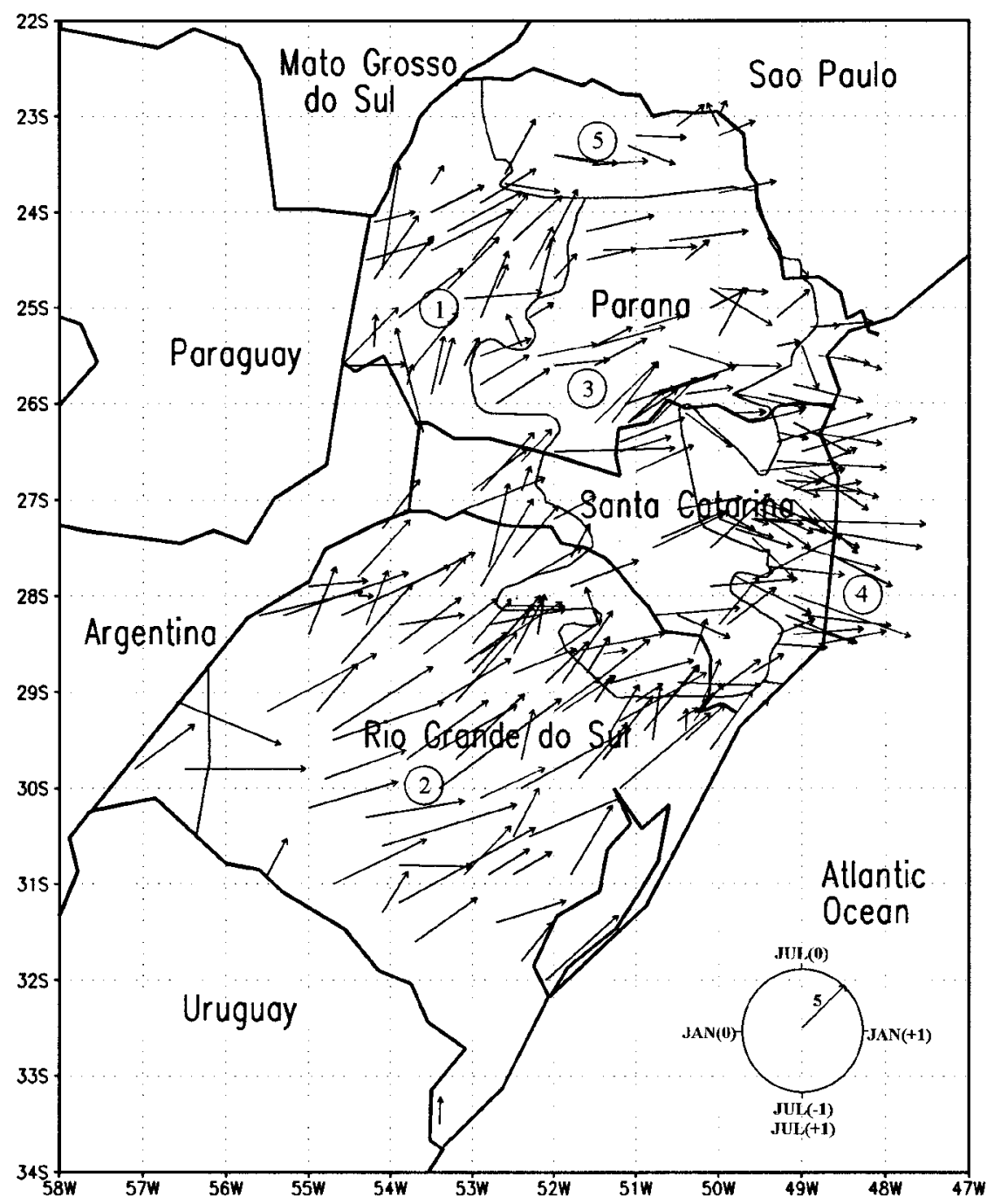

FIG. 4. Amplitudes and phases of the first harmonic fitted to composites of monthly percentile ranks of precipitation for El Niño events in the biennia from the July before to the June after the event years. The "vector clock" indicates the phases and magnitudes of the vectors. A horizontal vector pointing to the right indicates a maximum of the first harmonic in January after a warm event year, with time increasing clockwise.

less of particular kinds of events, we chose to use a wide set of episodes, which were qualified under a broad range of criteria (Table 1 ).

The basic list of El Niño events is that of Schneider and Fleer (1989), who also provided a measure of their intensity. These events were chosen according to the sea surface temperature (SST) anomaly averaged over the area $0^{\circ}-5^{\circ} \mathrm{S}$ and $130^{\circ}-80^{\circ} \mathrm{W}$. Other events, defined by Kiladis and Diaz (1989) and RH87, were also included. Kiladis and Diaz (1989) based their definition on a standard Southern Oscillation index (SOI) combined with an SST anomaly index for the eastern Pacific $\left(4^{\circ} \mathrm{N}-4^{\circ} \mathrm{S}\right.$, $130^{\circ} \mathrm{W}$ to the South American coast). RH87 used the list of events of Rasmusson and Carpenter (1983), based on SST data near the South American coast $\left(4^{\circ}-12^{\circ} \mathrm{S}\right)$, and Quinn et al. (1978). Besides, we added events for which the 5-month running means of the monthly SST anomalies averaged for the Niño 3 region $\left(5^{\circ} \mathrm{N}-5^{\circ} \mathrm{S}\right.$, $\left.150^{\circ}-90^{\circ} \mathrm{W}\right)$ are $+0.5^{\circ} \mathrm{C}$ or more for at least six consecutive months (Trenberth 1996b).

Based on similar reasoning, we take the La Niña years from RH89 and Kiladis and Diaz (1989). Ropelewski and Halpert used the SOI to define them, whereas Kiladis and Diaz defined them as having characteristics opposite to those prescribed for El Niño events. Additionally, we included events based on the SST anomaly index for the Niño 3 region, but for negative anomalies. In the cases of consecutive La Niña episode years, only the first one is used as year (0) in the composites (i.e., 1916, 1949, 1954, and 1970). 


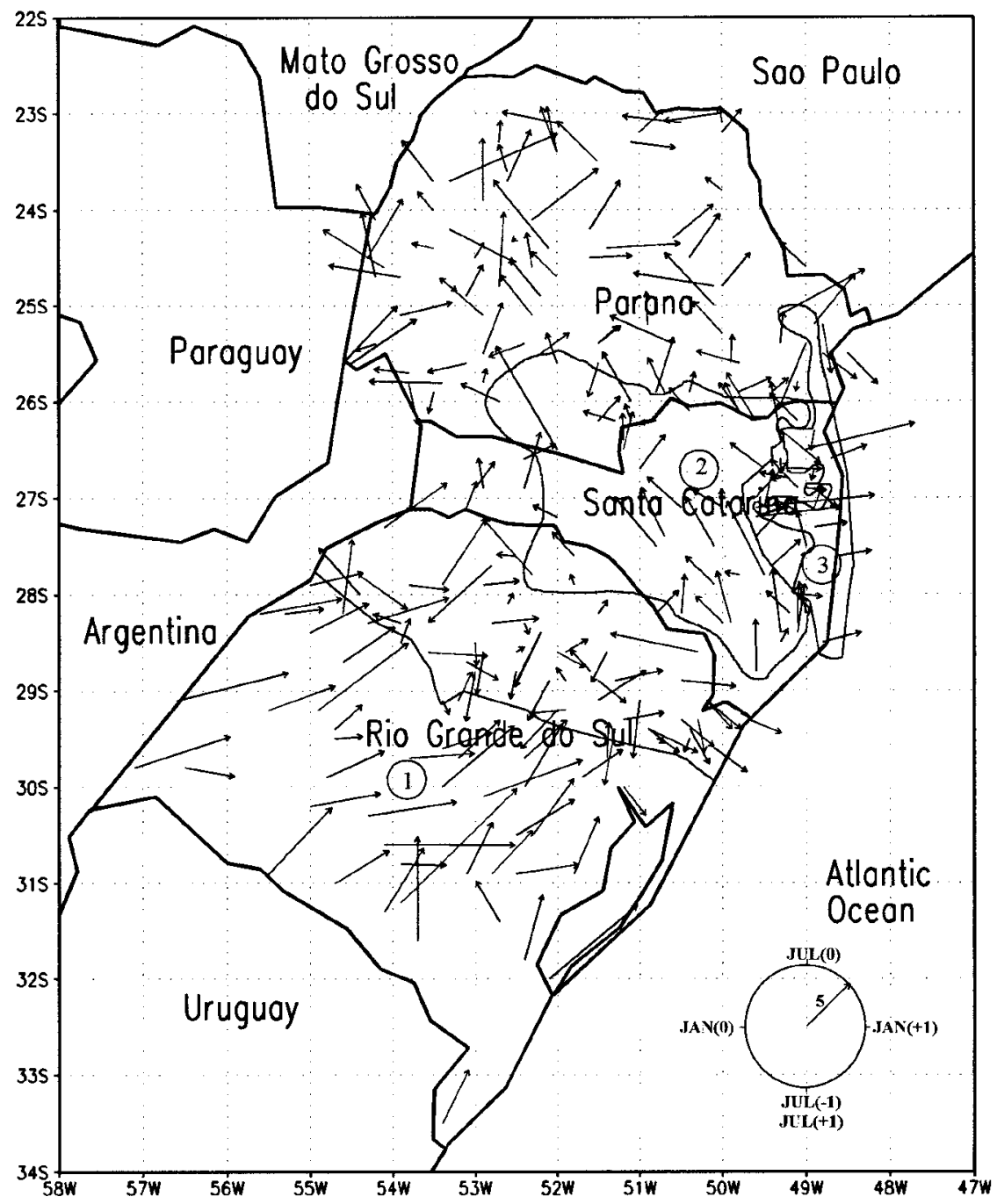

FIG. 5. Amplitudes and phases of the first harmonic fitted to composites of monthly percentile ranks of precipitation for La Niña events in the biennia from the July before to the June after the event years. The vector clock indicates the phases and magnitudes of the vectors. A horizontal vector pointing to the right indicates a minimum of the first harmonic in January after a warm event year, with time increasing clockwise.

\section{c. Some relief features}

Figure 2 shows the contours of surface elevation from the mean sea level in southern Brazil. There are large regions of plateaus in Paraná and Santa Catarina above $800 \mathrm{~m}$ with height decreasing to the west. They are separated from the low coastal regions by chains of mountains. Apart from its northeastern region, slightly wavy low plains dominate Rio Grande do Sul. This orography contributes to establishing some east-west differences in the rainfall regimes.

\section{d. Climatic regimes of rainfall}

The peak wet season has distinct timings in different locations in southern Brazil, indicating distinct climatic regimes of rainfall (Fig. 3). Most of Paraná and centraleastern Santa Catarina show unimodal variation with a peak rainy season in austral summer, which is indicative of a subtropical summer monsoon climate. There is a transitional region encompassing southwestern Santa Catarina and most of Rio Grande do Sul, where the peak wet season changes from summer to spring and then to late winter, across a phase discontinuity. In the southeastern part of the state of Rio Grande do Sul the peak rainy season is the austral winter. This characterizes a midlatitude regime, where the rainfall is due to frontal penetration associated with migratory extratropical cyclones. The relief may be responsible for the different peak wet seasons at the southern coast of Brazil. The summer peak wet season in January, February, and March only holds where there is an orographic barrier 
TABLE 3. Characteristics of the homogeneous subregions for El Niño-related precipitation.

\begin{tabular}{|c|c|c|c|c|c|}
\hline & \multicolumn{5}{|c|}{ Region } \\
\hline & 1 & 2 & 3 & 4 & 5 \\
\hline Spatial coherence index & 0.92 & 0.95 & 0.95 & 0.96 & 0.88 \\
\hline Amplitude of the vectorial mean & 4.60 & 5.64 & 4.82 & 5.33 & 3.84 \\
\hline Phase of the vectorial mean & 23.8 & 15.7 & 24.7 & 1.3 & 12.0 \\
\hline (peak date: day/month) & $\operatorname{Sep}(0)$ & $\operatorname{Oct}(0)$ & $\operatorname{Nov}(0)$ & $\operatorname{Feb}(+)$ & $\operatorname{Jan}(+)$ \\
\hline
\end{tabular}

near the coast, as in Paraná, Santa Catarina, and northern Rio Grande do Sul. In this area the orography probably intensifies the land-sea temperature contrast and associated sea-land breeze through an elevated heat source.

Significant bimodal variation of rainfall occurs in several parts of southern Brazil, defining the character of transitional regions. This behavior is probably caused by the interference of two adjacent regimes: summer monsoon and midlatitude winter conditions, which are responsible for the peak rainy seasons in January and July, respectively. Bimodal variation dominates in southwestern Rio Grande do Sul, with wet seasons in autumn and spring, and northeastern Rio Grande do Sul, with maxima in winter and summer. An annual cycle with three peaks is characteristic of southwestern Paraná, western Santa Catarina, and northwestern-central Rio Grande do Sul. This regime is strongly influenced by the mesoscale convective complexes in northeastern Argentina, eastern Paraguay, and the western part of southern Brazil (Velasco and Fritsch 1987). Their intensification is related to the seasonal change of the upper-tropospheric subtropical jet.

\section{Methodology}

The analysis method is based on RH87 and is outlined below. The first three steps are intended for analyzing the spatial structure of the rainfall anomalies associated with El Niño (La Niña) events, giving also a first estimation of their magnitudes.

1) The monthly precipitation data are represented at each station as percentile ranks to place the station precipitation anomalies on an equal footing. For each station, a warm (cold) episode composite of the percentile ranked precipitation is formed for the 24-month period from July of the year before $[\operatorname{Jul}(-)]$ to June of the year after an episode $[\operatorname{Jun}(+)]$.

TABLE 4. Characteristics of the homogeneous subregions for La Niña-related precipitation.

\begin{tabular}{lccc}
\hline \hline & \multicolumn{3}{c}{ Region } \\
\cline { 2 - 4 } & 1 & 2 & 3 \\
\hline Spatial coherence index & 0.90 & 0.88 & 0.92 \\
Amplitude of the vectorial mean & 5.22 & 2.96 & 3.86 \\
Phase of the vectorial mean & 15.5 & 25.1 & 11.7 \\
(peak date:day/month) & $\operatorname{Oct}(0)$ & Jun $(0)$ & Nov(0) \\
\hline
\end{tabular}

2) The first Fourier harmonic of each composite, for the idealized 24-month period from $\operatorname{Jul}(-)$ to $\operatorname{Jun}(+)$, is determined. The first harmonic (amplitude and phase) is represented as a vector and plotted. We use the convention that the phase of the vector refers to the maximum (minimum) of the first harmonic for warm (cold) episodes, because there is a tendency to more (less) than normal precipitation during these episodes.

3) Subregions of spatially coherent warm (cold) episode-related rainfall anomalies are selected, where the amplitudes of the vectors are relatively large and the phases are similar or coherent. This selection seeks the maximization of a measure of coherence, which is given by the ratio of the magnitude of the vector sum to the sum of the magnitudes of the vectors for all the stations in a subregion.

Each of these areas is subjected to the following further analysis to determine the periods with largest anomalies and assess their consistency during warm (cold) events.

4) Time series of monthly rainfall for each station are transformed into time series of precipitation percentiles based on gamma distributions fit to the data of each calendar month.

5) Warm (cold) event composites are formed from the precipitation percentiles for each station in a coherent subregion for the 36-month period from $\operatorname{Jan}(-)$ to $\operatorname{Dec}(+)$. These composites are then averaged to form a warm (cold) event "aggregate" composite for each coherent subregion. This aggregate composite is used to identify the periods with the largest anomalies within the SO cycle. The period was extended in relation to that of RH87 to allow the detection of anomalies a little before and after the biennia Jul(-)-Jun(+), because late anomalies were observed in some regions of southern Brazil in recent episodes.

6) Time series of station-averaged precipitation percentiles for the periods identified in step 5 are analyzed in order to assess the statistical significance of the relationship between warm (cold) events and rainfall anomalies. The hypothesis is tested that these periods are especially wet or especially dry during these events, by using the hypergeometric distribution. This distribution gives the probability of obtaining $k$ dry (wet) episodes in $r$ trials [number of warm (cold) episodes] from a population consisting of $n_{1}$ dry and $n_{2}$ wet samples. Let us suppose that a particular series of precipitation percentiles embraces $r$ warm episodes and that 
Subregion 01

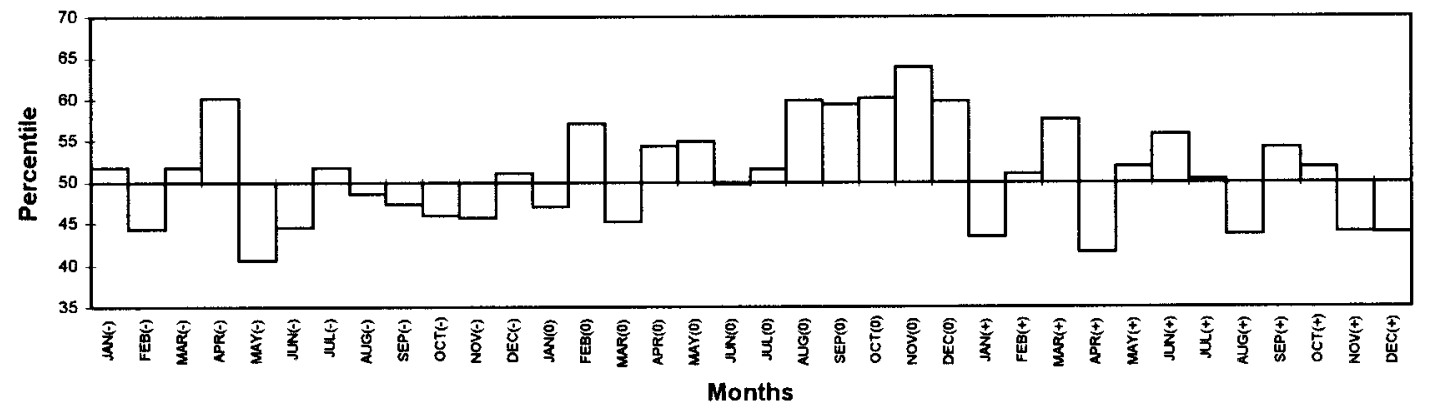

Subregion 02

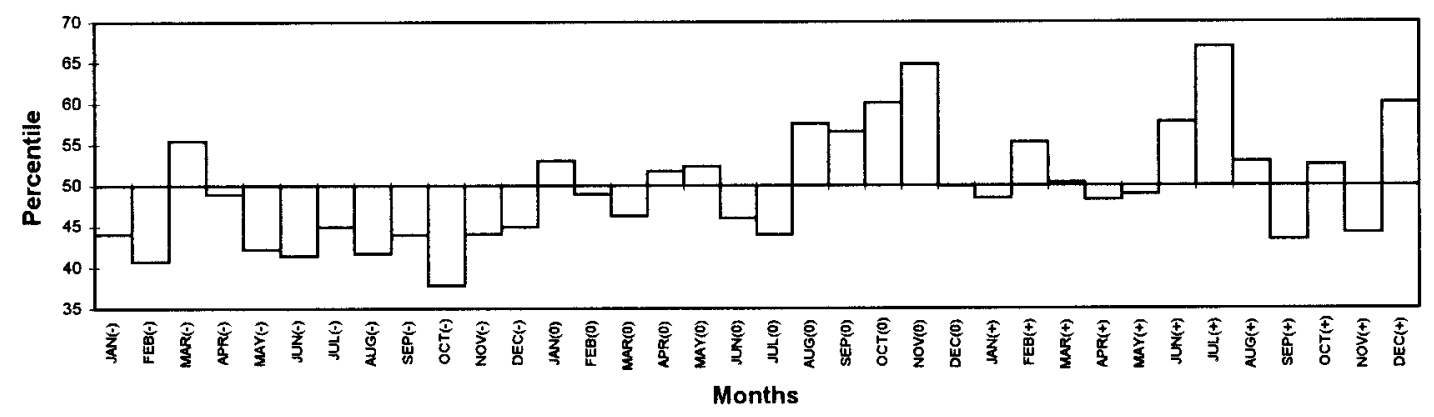

Subregion 03

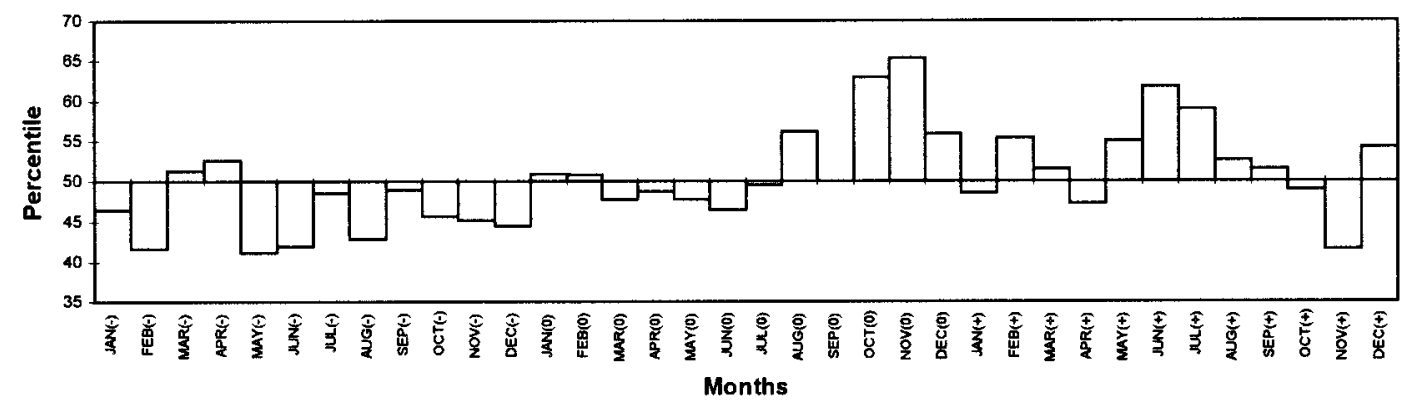

FIG. 6. Aggregate composite (average gamma percentiles) for the 36-month period centered on an El Niño year for each coherent subregion in Fig. 4.

there was dryness in $k$ of them. In the case of testing whether this period is consistently wetter during these episodes, the probabilities of obtaining more than $k$ dry cases in that sample of $r$ episodes, that is, the cumulative probabilities of obtaining $k+1, k+2, \ldots$, up to $r$ dry cases, are computed. This will give the significance level of this relationship of warm episode-wet condition.

Some issues related to the methodology will be discussed in the following section.

\section{Questions related to the method}

The first question is related to the analysis of the spatial structure of the El Niño (La Niña)-related anomalies: is the first harmonic fitted to the 24-month composite from $\operatorname{Jul}(-)$ to $\operatorname{Jun}(+)$ able to identify coherent subregions in southern Brazil? To answer this question some tests were carried out with El Niño events. The results are shown for 16 stations in central Paraná; half of them are located in each of two coherent subregions, 
Subregion 04

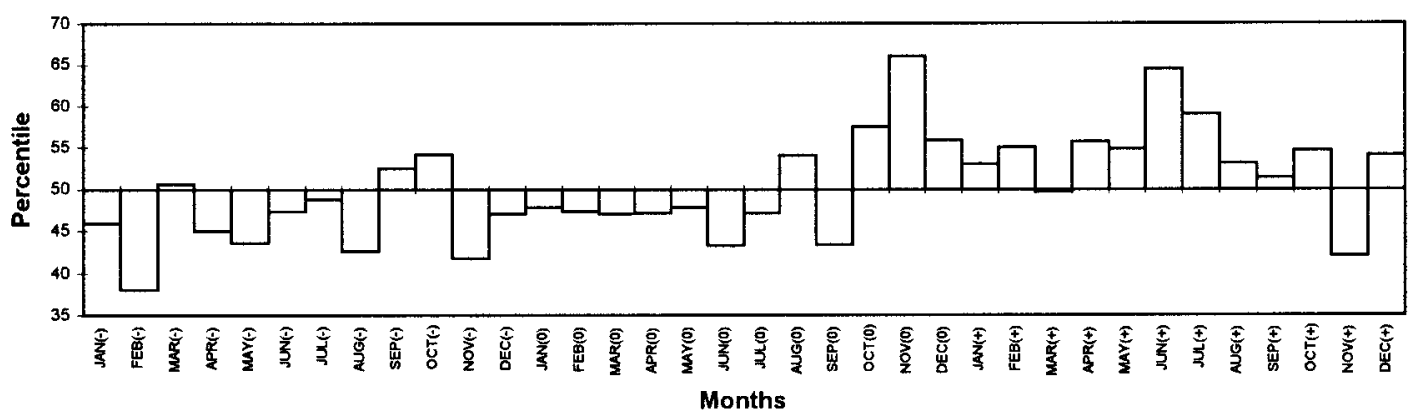

Subregion 05

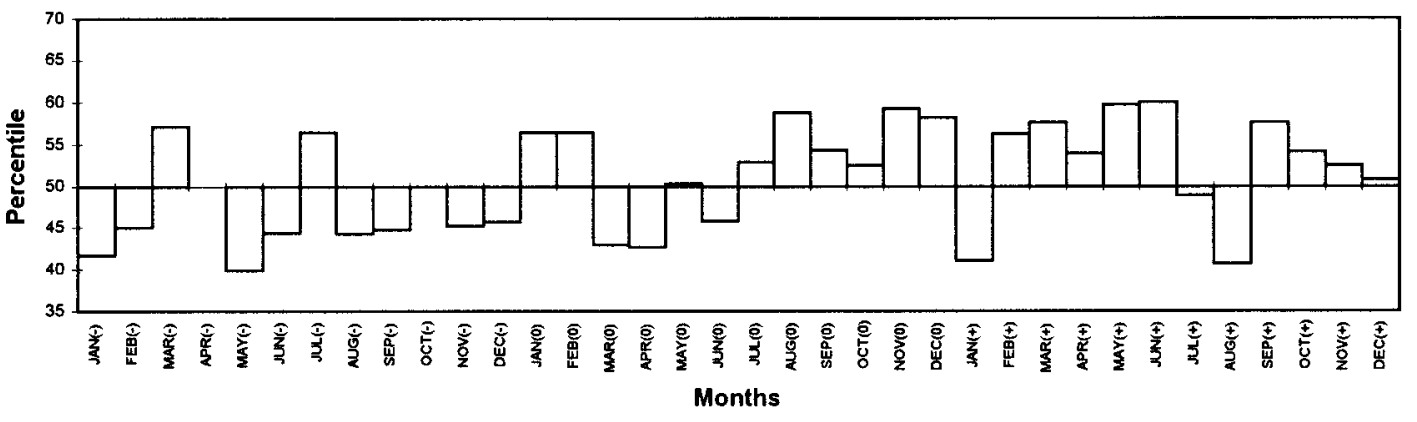

FIG. 6. (Continued)

A and B (corresponding to parts of the subregions I and III, defined later in this paper). The first three steps described in the previous section are carried out using several different periods for the composites. Table 2 shows how the index of spatial coherence changes for different periods. It lessens significantly whenever the two subregions are merged, with the exception of the $\operatorname{Jan}(-)-\operatorname{Dec}(0)$ period, for which the values (which are small) remain almost the same. The most significant reduction of the spatial coherence for the merged region occurs for the $\operatorname{Jan}(0)-\operatorname{Dec}(+)$ period. These results indicate that there are significant El Niño-related rainfall anomalies in the year $(+)$ and that they behave differently in the two subregions. Any of the periods that include at least the first half of the year $(+)$ is able to separate the coherent subregions. However, increasing the size of the "compositing" window beyond the periods of significant anomalies does not increase the coherence because nonconsistent random anomalies would be included. Among the 24- and 30-month "compositing" windows, those that best cover the SO-related anomalies are $\operatorname{Jul}(-)$ to $\operatorname{Jun}(+)$ and $\operatorname{Jul}(-)$ to $\operatorname{Dec}(+)$. That is why they produce the highest coherences for subregions $\mathrm{A}$ and $\mathrm{B}$, besides a large decrease for the subregion $\mathrm{A}+\mathrm{B}$. A further expansion of these windows to $\operatorname{Jan}(-)$ to $\operatorname{Dec}(+)$ causes the decrease of the coherence. We chose the window $\operatorname{Jul}(-)-\operatorname{Jun}(+)$ because it produces high coherence for both subregions and allows comparison with the results of RH87.

There is more than one precipitation maximum or minimum associated with El Niño events over that 24-month period in southern Brazil. The first harmonic usually accounts for the largest or second largest amount of the variance. However, there are often higher harmonics that account for a larger percentage of the variance than the first harmonic (most frequently just above one season, 3.4 months). This higher-frequency response is due to the interaction between the low-frequency-large-scale anomalies associated with El Niño and the mechanisms associated with the local annual cycle of precipitation, as well as land surface processes. The first harmonic is adequate for the definition of the coherent subregions, provided that the most significant anomalies are included in the period of the composites. However, it is most efficient in characterizing the timing of the precipitation anomalies only for those stations with one strong maximum or minimum. Therefore, this characterization will be carried out in step 5 , through the analysis of the warm (cold) event aggregate composites.

The second question refers to the detailed analysis of 
Subregion 01

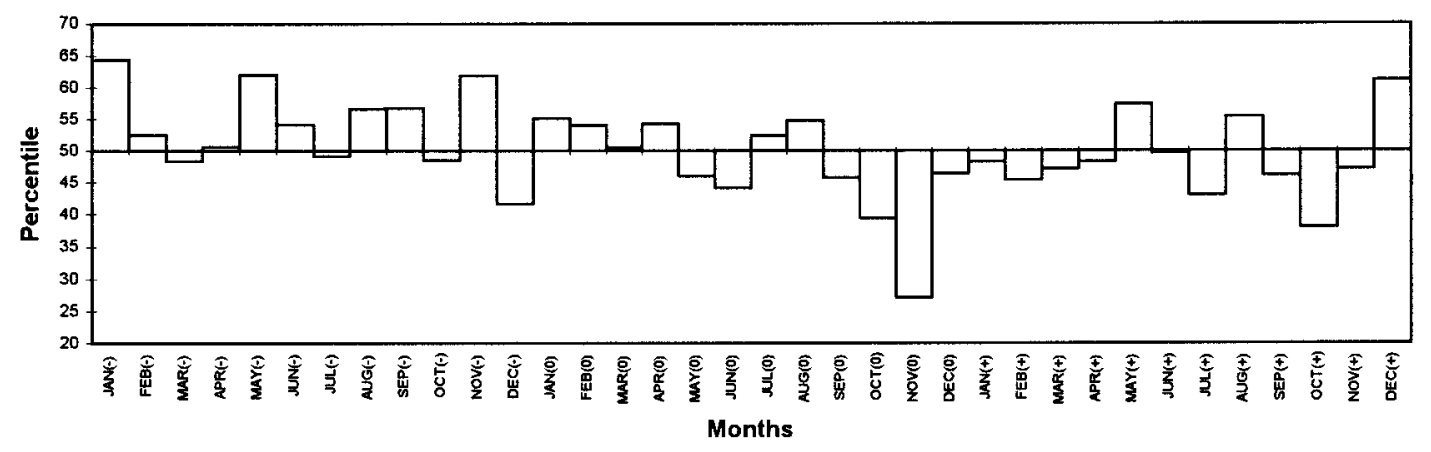

Subregion 2

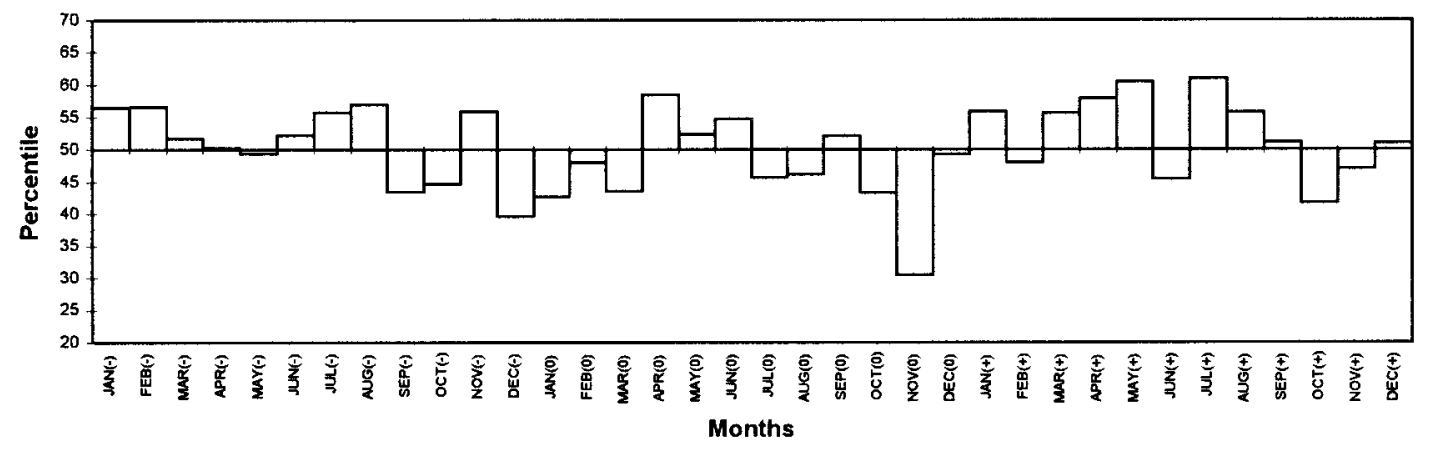

Subregion 3

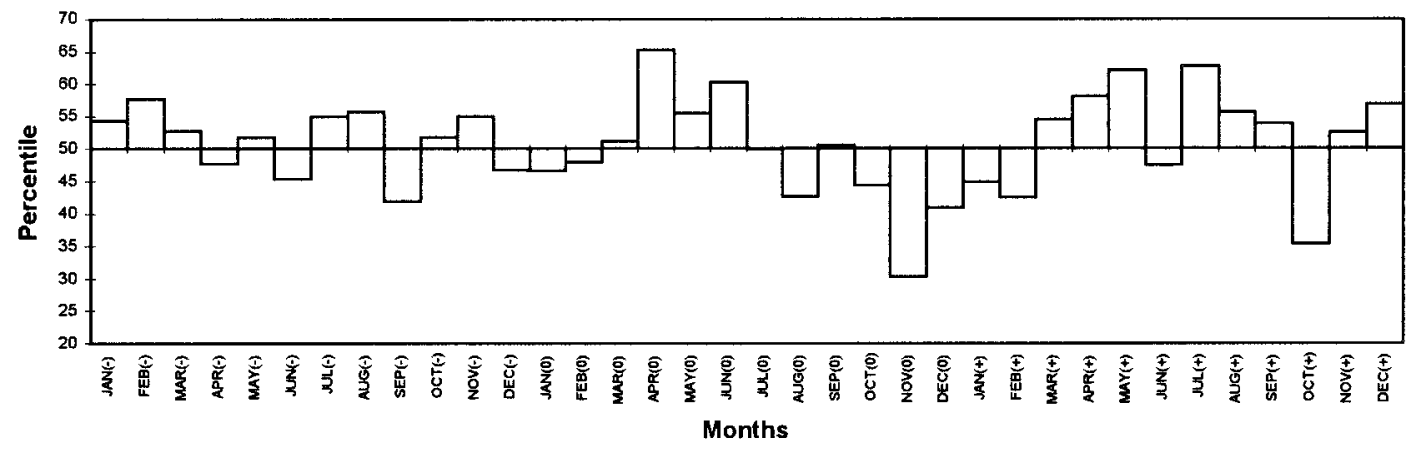

FIG. 7. Aggregate composite (average gamma percentiles) for the 36-month period centered on a La Niña year for each coherent subregion in Fig. 5.

the anomalies: what are the implications of using a 36month composite when this relatively long period will include several cases that overlap the previous (or following) warm or cold episode? First of all, it is important to stress that the 36-month composite is used only to identify the periods with the largest anomalies within the SO cycle. Afterward, these anomalies are submitted to a test of consistency. If there were anomalies caused only by some overlaps of previous (or following) episodes, they would not be consistent along the whole assemblage of El Niño or La Niña events. To prevent the possibility of missing some consistent anomaly because its magnitude was diminished by overlaps, the consistency of the anomalies is systematically tested over running seasons. Therefore, when two events overlap, only the magnitude of the anomalies in the composite might be affected, and, even so, 


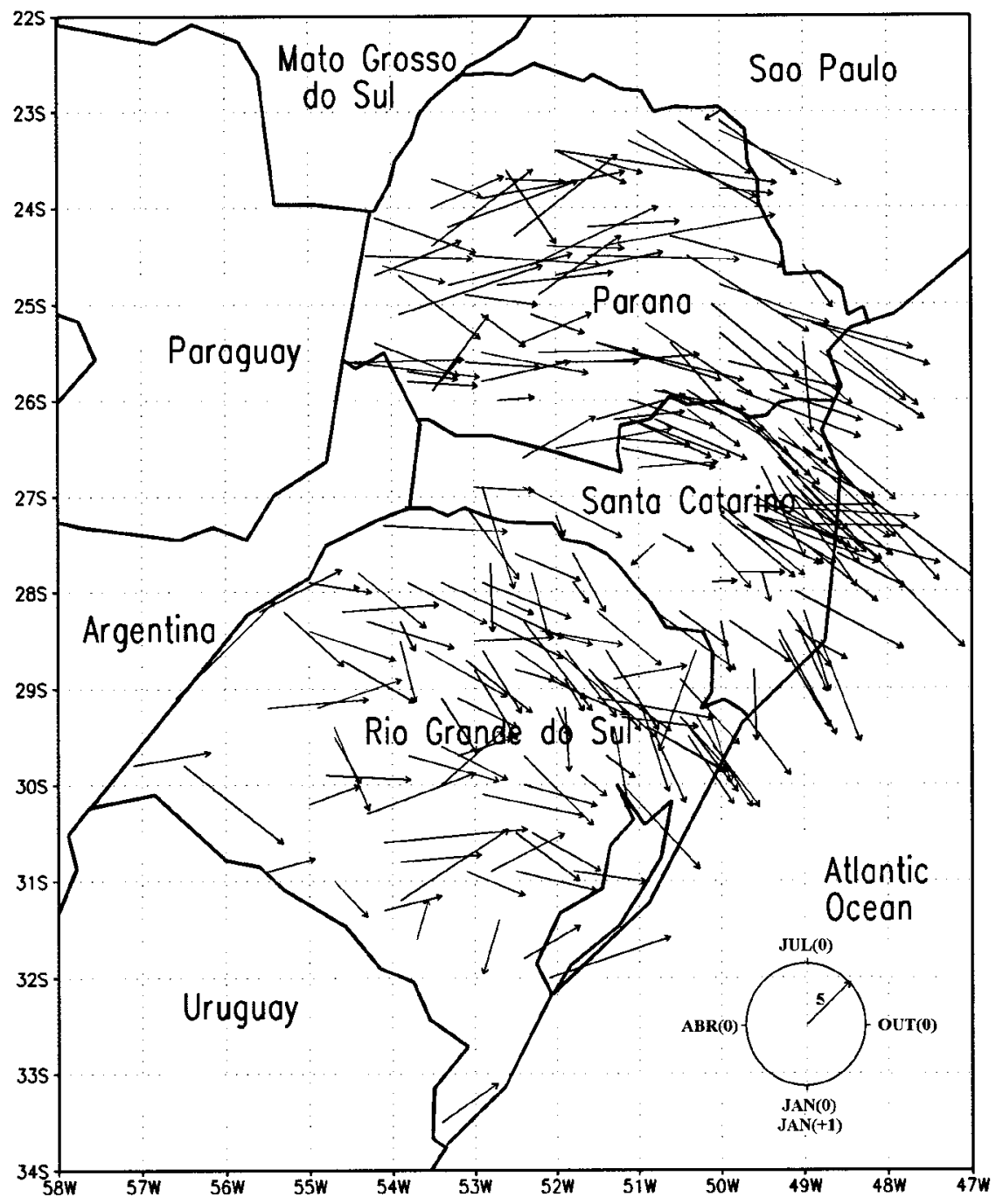

FIG. 8. Amplitudes and phases of the first harmonic fitted to composites of monthly percentile ranks of precipitation for La Niña events in the period from January to December of the event year. The vector clock indicates the phases and magnitudes of the vectors. A horizontal vector pointing to the right indicates a minimum of the first harmonic in the beginning of October, with time increasing clockwise.

only if two consistent anomalies are overlapping. The implications in the worst cases are discussed in the presentation of the results.

\section{Results}

The vectors representing the maximum (minimum) of the first harmonic of the composite percentile precipitation from $\operatorname{Jul}(-)$ to $\operatorname{Jun}(+)$ for warm (cold) events are plotted in Figs. 4 and 5.

Four subregions of coherent behavior with respect to precipitation anomalies during warm events are determined on the basis of the maximization of the index of coherence (Fig. 4). Their characteristics are displayed in Table 3. Relief, latitude, and proximity to the Atlantic Ocean determine the limits between the subregions. The subregion 3, for instance, corresponds nearly to the area with average altitude of $800 \mathrm{~m}$. Subregion 5 embraces too few stations and is not analyzed here because it will undergo further study with the region to the north.

For rainfall anomalies associated with cold episodes, it is possible to determine only three coherent regions based on the first harmonic vectors of the Jul( - - $-\mathrm{Jun}(+)$ composites (Fig. 5). Their characteristics are displayed in Table 4. The phase of the vectors in this case refers to the minimum of the first harmonic. The reasons of the apparent decrease of coherence concerning rainfall anomalies during cold events will be analyzed later on.

The warm event "aggregate" composites (average gamma percentiles) for each coherent subregion in Fig. 4 are shown in Fig. 6 for the 36-month period centered on a warm event year. For all of the subregions in south- 
Subregion 1

Aug(0) - Dec(0)

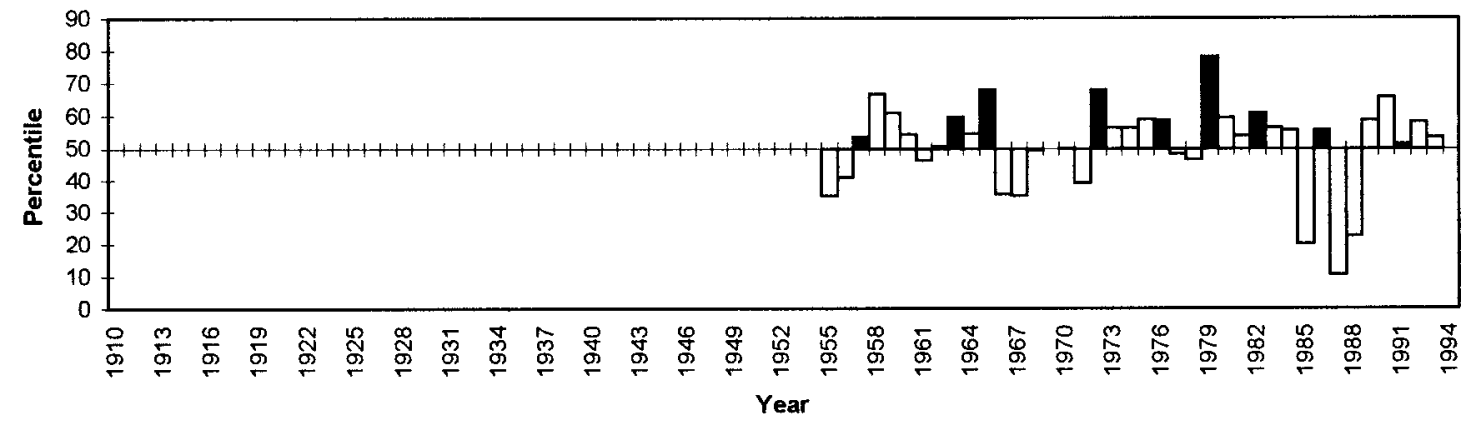

Subregion 2

$\operatorname{Sep}(0)-\operatorname{Dec}(0)$

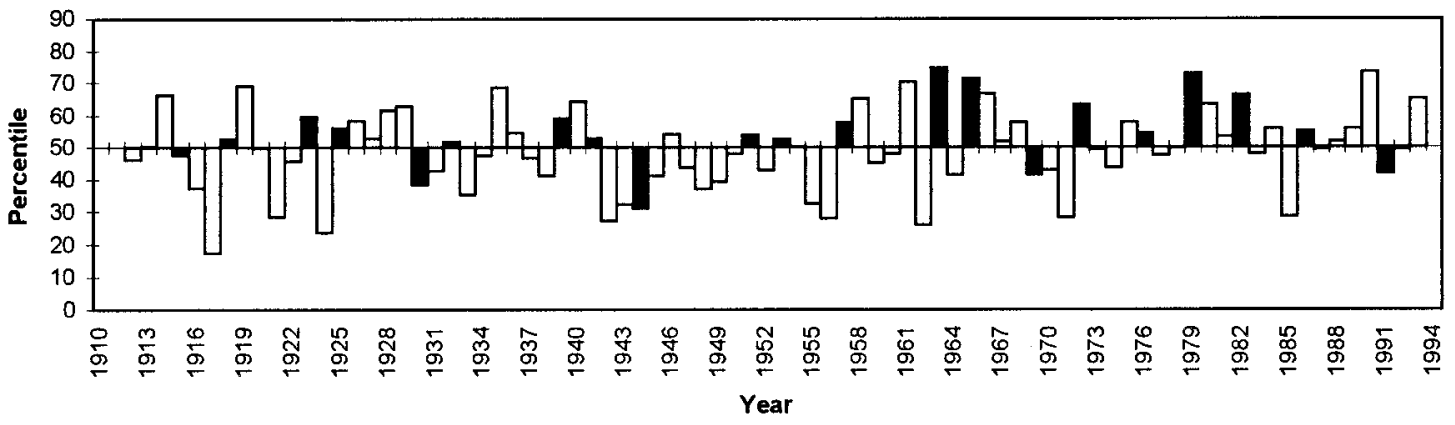

FIG. 9. Time series of station-averaged precipitation percentiles within the indicated subregions for periods in spring-summer. The black bars represent El Niño years.

TABLE 5. Level of significance of the hypothesis test that the indicated periods are wetter or drier than normal during El Niño events within the four coherent subregions (values $\geq 95$ are bold). The periods (three or more months) that present the largest significance (above $95 \%$ ) are marked $(*)$.

\begin{tabular}{lcccc}
\hline \hline & \multicolumn{4}{c}{ Subregion } \\
\cline { 2 - 5 } \multicolumn{1}{c}{ Period } & 1 & 2 & 3 & 4 \\
\hline May(-)-Jun(-)(dry) & 76.7 & 77.8 & 83.3 & 53.0 \\
May(-)-Dec(-)(dry) & 85.1 & $\mathbf{9 8 . 6}$ & $\mathbf{9 8 . 4} *$ & 91.2 \\
May(-)-Jul(0)(dry) & 74.3 & 81.9 & $\mathbf{9 8 . 4}$ & 94.4 \\
Aug(-)-Nov(-)(dry) & 85.1 & $\mathbf{9 9 . 2} *$ & $\mathbf{9 5 . 9}$ & $\mathbf{9 7 . 3}$ \\
Aug(-)-Dec(-)(dry) & 87.0 & $\mathbf{9 8 . 3}$ & $\mathbf{9 7 . 1}$ & 78.4 \\
Aug(0)-Nov(0)(wet) & $\mathbf{9 7 . 8}$ & $\mathbf{9 8 . 3}$ & $\mathbf{9 7 . 1}$ & $\mathbf{9 8 . 1}$ \\
Aug(0)-Dec(0)(wet) & $\mathbf{9 8 . 7} *$ & 91.7 & $\mathbf{9 9 . 1}$ & $\mathbf{9 8 . 1}$ \\
Sep(0)-Nov(0)(wet) & 84.3 & $\mathbf{9 7 . 7}$ & $\mathbf{9 9 . 9}$ & 82.5 \\
Sep(0)-Dec(0)(wet) & 91.7 & $\mathbf{9 9 . 8 *}$ & $\mathbf{9 9 . 9 9 *}$ & $\mathbf{9 7 . 3}$ \\
Oct(0)-Nov(0)(wet) & 73.4 & 86.1 & $\mathbf{9 9 . 9 9 *}$ & $\mathbf{9 9 . 6}$ \\
Oct(0)-Dec(0)(wet) & 88.5 & 86.7 & $\mathbf{9 9 . 7}$ & $\mathbf{9 9 . 9}$ \\
Apr(+)-Jul(+)(wet) & 9.6 & 89.6 & 59.5 & $\mathbf{9 6 . 2 *}$ \\
Apr(+-Aug(+)(wet) & 13.7 & $\mathbf{9 5 . 2}$ & 69.9 & 91.2 \\
May(+)-Jul(+)(wet) & 57.7 & $\mathbf{9 7 . 3 *}$ & 76.8 & 88.6 \\
May(+)-Aug(+)(wet) & 29.2 & $\mathbf{9 6 . 3}$ & 64.1 & 82.5 \\
Jun(+)-Jul(+)(wet) & 35.8 & 94.5 & $\mathbf{9 9 . 4}$ & $\mathbf{9 8 . 7}$ \\
Jun(+)-Aug(+)(wet) & 64.2 & $\mathbf{9 7 . 0}$ & $\mathbf{9 5 . 3 *}$ & 85.4 \\
\hline
\end{tabular}

ern Brazil the average gamma percentile reaches 65 or more during the season of largest anomalies, whereas for the "core region" of RH87 in Argentina and Uruguay, it does not exceed 60.

There are large positive rainfall anomalies during the spring of the warm event year over all of the subregions, being the most persistent ones those in subregion 1 , in western Paraná. Subregions 2, 3, and 4 present also positive anomalies in the autumn-winter of the following year, the most persistent of which are in subregion 4 , in the easternmost part of southern Brazil. A tendency to dryness is visible during most of the year before a warm event and the first half of the warm event year. It is possible to see that the month in which the maximum of the first harmonic is reached does not always correspond to the month of the maximum anomaly. For instance, in subregion 4 the largest anomalies occur in $\operatorname{Nov}(0)$ and $\operatorname{Jun}(+)$ and the maximum of the first harmonic is reached in the beginning of Feb $(+)$.

The cold event aggregate composites for the three coherent subregions in Fig. 5 are shown in Fig. 7, for the 36-month period centered on a cold event year. The average gamma percentile reaches 30 or less during the 

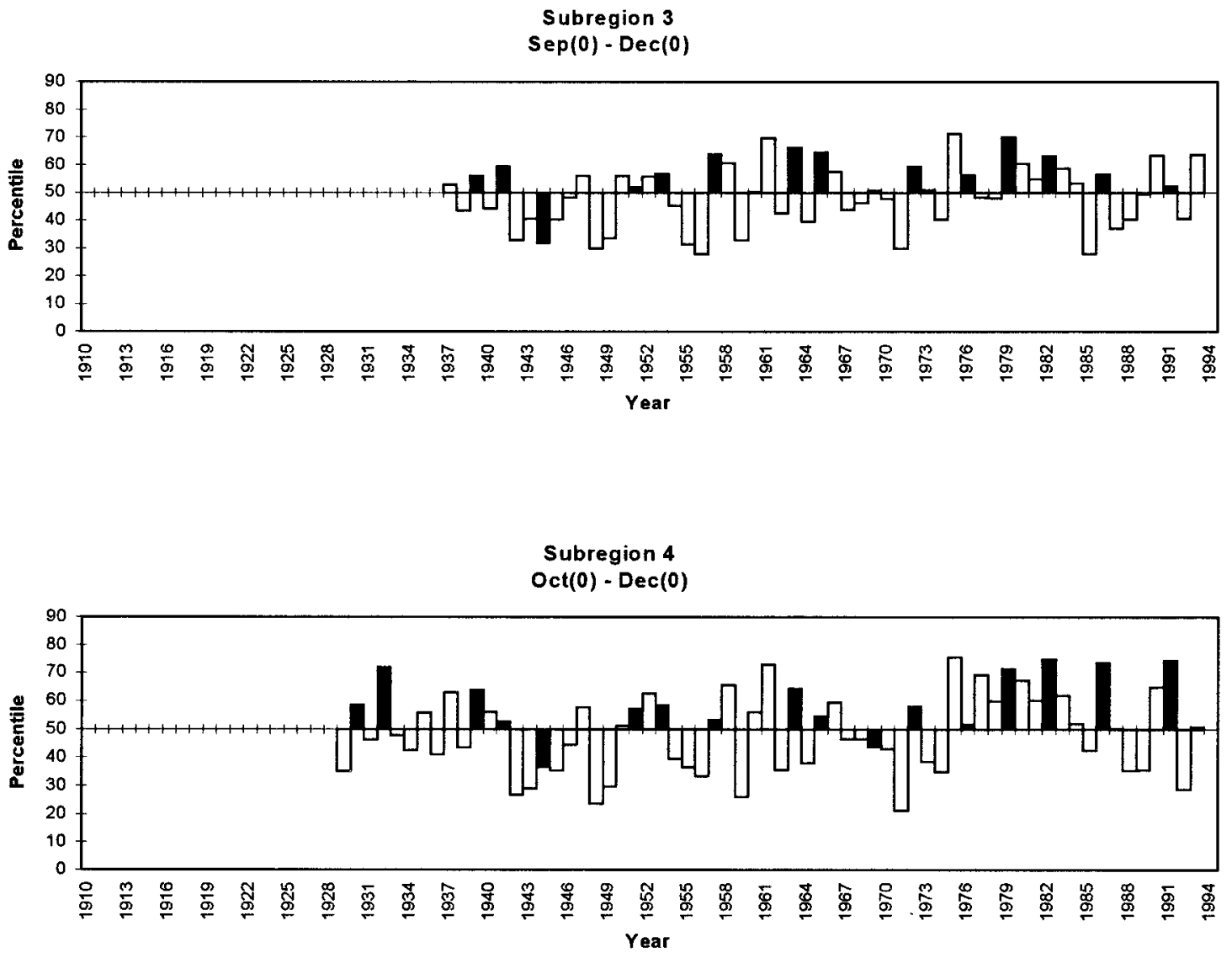

FIG. 9. (Continued)

season of largest anomalies, whereas the minimum values of RH89 for the core region in southeastern South America remain around 40.

Although there is a different distribution of anomalies for the three subregions over the 36-month period, there is a common period of strong negative anomalies during the spring of the cold event years, particularly $\operatorname{Oct}(0)$ $\operatorname{Nov}(0)$. This feature suggests that, in spite of the differences, there are negative anomalies during this period all over southern Brazil. In order to disregard the effect of the anomalies in the years $(-)$ and $(+)$, which are considerably different for the three subregions and responsible for the decrease of coherence, only the period $\operatorname{Jan}(0)-\operatorname{Dec}(0)$ is considered for another computation of the first harmonic.

The new map of first harmonic vectors for this period (Fig. 8) shows larger magnitudes and greater coherence than that for the period $\operatorname{Jul}(-)-\operatorname{Jun}(+)$. Their phases indicate that there is a minimum of precipitation in the second semester of cold event years all over southern Brazil.

Although the composites of Figs. 6 and 7 are useful to identify the periods with largest average anomalies during the warm (cold) event cycle, the magnitude is not sufficient, in itself, to establish the consistency of these anomalies during these events. Outliers and overlaps may have influenced it. Therefore, time series of station-averaged precipitation percentiles for selected periods within each subregion are analyzed according to step 6 of section 3. Table 5, based on this analysis, shows the statistical significance of the hypothesis test, based on the hypergeometric distribution, that these periods are wetter (or drier) than normal during El Niño events. Periods shorter than three months are also tested in an attempt to more precisely localize the most consistent anomalies in the warm event cycle. The wet anomalies during the spring of the El Niño year are highly consistent all over southern Brazil. Wet anomalies in the winter of the year after El Niño and dry anomalies in the year before are also consistent, except in subregion 1. The periods (embracing three or more months) that present the largest significance (greater than $95 \%$ ) for each subregion are marked. It is possible to see that it is not always the periods with the largest anomalies in Fig. 6 that are the most consistent ones. This becomes clear by comparing, for example, the levels of significance for May(+)-Jul(+) and Jun(+)$\operatorname{Aug}(+)$, for subregion 3. This may be explained by the influence of outliers or overlaps on some average anomalies in Fig. 6. 
Subregion 2

Mayl+) - Jul(+)

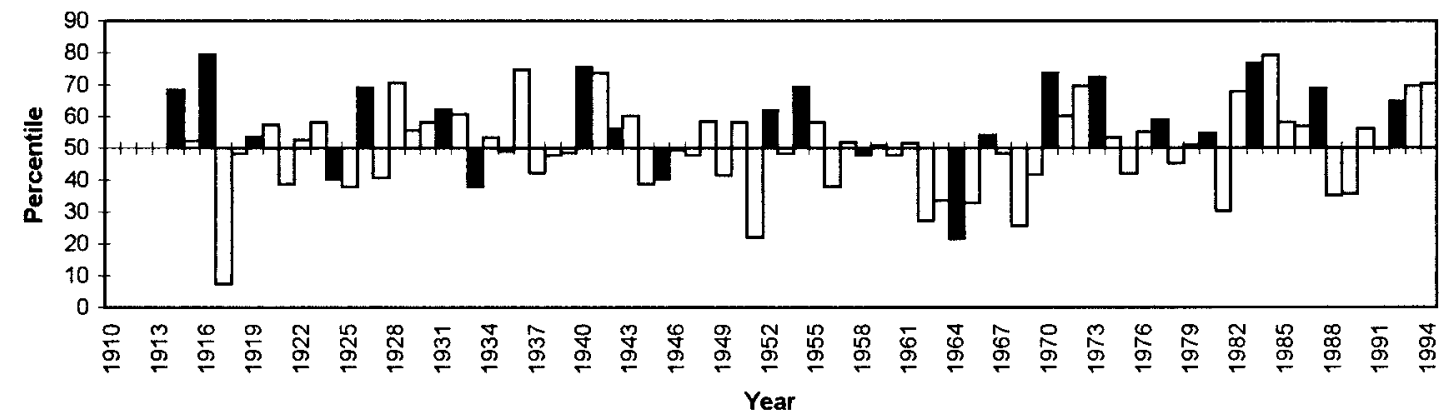

Subregion 3

Jun(+) - Aug(+)

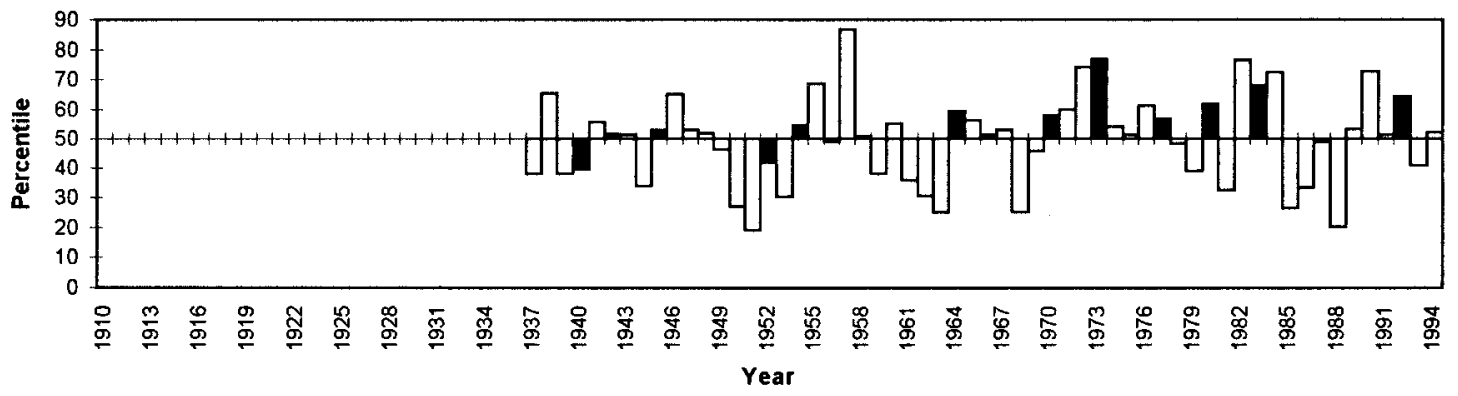

Subregion 4

Apr(+) - Jul(+)

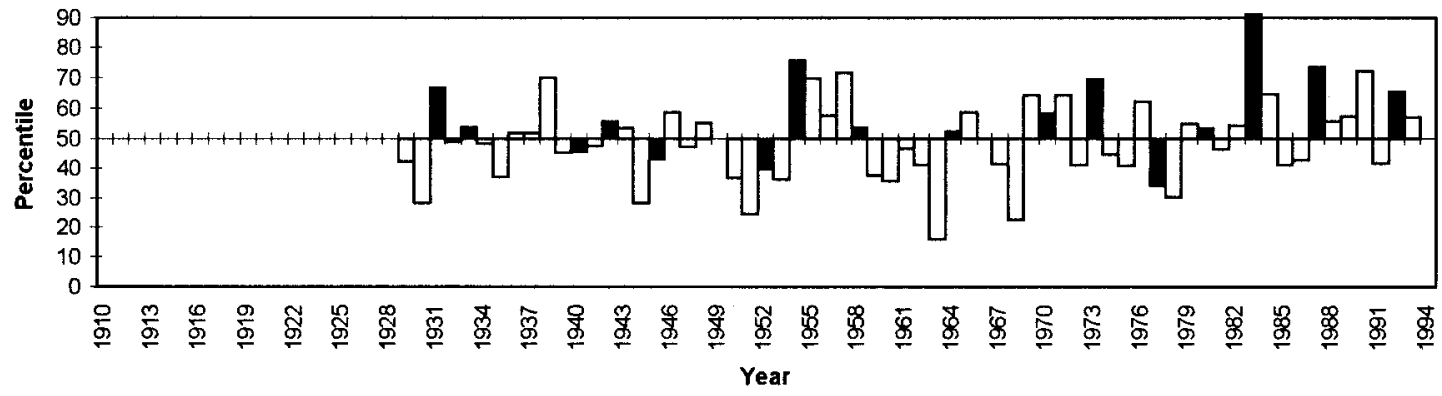

FIG. 10. Time series of station-averaged precipitation percentiles within the indicated subregions for periods in autumn-winter. The black bars represent years after an El Niño year.

Figures 9 and 10 show the time series of precipitation percentiles for periods with largest significance level during warm events in each subregion. These figures show that precipitation anomalies during these periods are predominantly positive in warm events and are among the strongest in the series.

Table 6 shows the statistical significance of the hypothesis test that selected periods are drier (or wetter) 
TABLE 6. Level of significance of the hypothesis test that the indicated periods are wetter or drier than normal during La Niña events within the three coherent subregions (values $\geq 95$ are bold). The periods (three or more months) that present the largest significance (above $95 \%$ ) are marked (*).

\begin{tabular}{llll}
\hline \hline & \multicolumn{3}{c}{ Subregion } \\
\cline { 2 - 4 } \multicolumn{1}{c}{ Period } & \multicolumn{1}{c}{1} & 2 & 3 \\
\hline May(-)-Jun(-)(wet) & 86.6 & 72.6 & 29.1 \\
May(-)-Jul(-)(wet) & 48.5 & $\mathbf{9 6 . 1}$ & 61.1 \\
May(-)-Aug(-)(wet) & 57.4 & $\mathbf{9 7 . 8 *}$ & 83.8 \\
Jun(-)-Aug(-)(wet) & 64.4 & 88.0 & 76.4 \\
Aug(-)-Sep(-)(wet) & $\mathbf{9 9 . 5 *}$ & 23.3 & 54.9 \\
Aug(-)-Nov(-)(wet) & $\mathbf{9 6 . 9}$ & 49.0 & 60.2 \\
Nov(-)(wet) & $\mathbf{9 8 . 9}$ & 38.9 & 66.1 \\
Apr(0)-Jun(0)(wet) & 11.4 & 63.6 & 94.3 \\
Jun(0)-Aug(0)(dry) & 67.4 & 58.7 & 7.4 \\
Aug(0)-Dec(0)(dry) & $\mathbf{9 9 . 9 9 *}$ & $\mathbf{9 5 . 6}$ & $\mathbf{9 9 . 3}$ \\
Aug(0)-Feb(+)(dry) & $\mathbf{9 9 . 8}$ & 91.5 & $\mathbf{9 9 . 6}$ \\
Sep(0)-Dec(0)(dry) & $\mathbf{9 9 . 9 6}$ & $\mathbf{9 9 . 7}$ & $\mathbf{9 9 . 1}$ \\
Sep(0)-Apr(+)(dry) & $\mathbf{9 8 . 6}$ & 93.4 & 85.4 \\
Oct(0)-Nov(0)(dry) & $\mathbf{9 9 . 9}$ & $\mathbf{9 9 . 0}$ & $\mathbf{9 9 . 5}$ \\
Oct(0)-Dec(0)(dry) & $\mathbf{9 9 . 4}$ & $\mathbf{9 9 . 8 *}$ & $\mathbf{9 9 . 5}$ \\
Oct(0)-Feb(+)(dry) & $\mathbf{9 9 . 9}$ & 94.9 & $\mathbf{9 9 . 6 *}$ \\
Mar(+)-May(+)(wet) & 19.5 & $\mathbf{9 5 . 0 *}$ & 76.4 \\
Mar(+)-Sep(+)(wet) & 10.5 & 86.7 & 80.3 \\
Jul(+)-Sep(+)(wet) & 22.8 & 74.9 & 70.9 \\
Oct(+)-Nov(+)(dry) & 61.4 & 29.4 & 66.1 \\
\hline
\end{tabular}

than normal during La Niña events. It is worth pointing out the high level of significance associated with the negative anomalies from $\operatorname{Oct}(0)$ to $\operatorname{Dec}(0)$ in all subregions. Their magnitudes are even stronger than that for El Niño-related anomalies. On the other hand, anomalies in the years $(-)$ and $(+)$ are consistent only over small areas. Subregions 1 and 2 show consistent wet anomalies in different periods of the year before La Niña and only in subregion 2 are there consistent anomalies in the year after La Niña.

Figure 11 shows time series of precipitation percentiles for periods relevant during the cold event cycle within the coherent subregions defined on the basis of the 24-month period from Jul $(-)$ to $\operatorname{Jun}(+)$. Although there are also negative precipitation anomalies in years without a cold event, most of the largest negative anomalies occur during such events.

As was mentioned in section 4 , the identification of consistent anomalies during the El Niño and La Niña cycles is not affected by the use of a 36-month composite of the anomalies, even if there are some cases of overlap. Only the magnitude of the anomalies might be affected. Even so, the change of magnitude is probably very small, because of the small proportion of overlaps. There are various types of overlaps whose possible outcomes are analyzed next.

When two events occur only 2 yr apart, year $(+)$ of the first overlaps year $(-)$ of the second. It may happen for two events of the same type or two opposite events. Among these possibilities, the only one potentially important here is the case of two warm events taking place
2 yr apart. It happened seven times for subregion 2, and four or less times for the other subregions, because the length of the data records is different for different subregions. As the anomalies are consistently dry in the year before and wet in the year after El Niño, this overlap would tend to diminish the magnitude of these anomalies. Although they are quite visible, even for subregion 2 (Fig. 6), one could expect them to be even larger.

Another type of overlap is due to consecutive episodes of the same nature. Fortunately, this is frequent neither for El Niño nor for La Niña. It happens four times for La Niña and in these cases only the first year of a sequence is used as year (0). The fact that these episodes last for more time than usual might produce a tendency to repeat the consistent negative anomalies of the year $(0)$ in the year $(+)$. There is no indication that this has happened. There are negative anomalies in $\operatorname{Oct}(+)$ and $\operatorname{Nov}(+)$ but they are not consistent.

The occurrence of consecutive episodes of opposite type is more frequent and is indicative of the biennial oscillation component in the Southern Oscillation. The composites include 11 (or less) consecutive sequences of cold/warm episodes and 9 (or less) consecutive sequences of warm/cold episodes. In these cases, years (0) and (+) of the first episode overlap years $(-)$ and (0) of the second one. Although the consistent dry anomalies in year (-) of El Niño are not exactly coincident with the consistent anomalies of year (0) of La Niña, they present a secondary maximum around $\operatorname{Oct}(-)-\operatorname{Nov}(-)$. On the other hand, the strong positive anomalies in the spring of year (0) of El Niño do not appear clearly in the composites of year (-) of La Niña. Only in subregion 1 (contained in subregion 2 of El Niño) are there consistent positive anomalies in $\operatorname{Aug}(-)-\operatorname{Nov}(-)$.

\section{Summary and discussion}

The analysis of a large dataset of monthly precipitation from 250 stations distributed all over southern Brazil shows that this region presents strong and consistent precipitation anomalies associated with El Niño and La Niña events. Their magnitude is even larger than in Argentina and Uruguay, which form the consistent SO-related precipitation core region of RH87 in southeastern South America. Besides the magnitude, there are several other differences between the results of RH87 for this region and the results for southern Brazil. They are the following.

1) While RH87 found a relatively low coherence for their core region of 0.81 , there are in southern Brazil subregions with great coherence (above 0.90) as regards the relationships between El Niño and rainfall during the period Jul( $(-)-J u n(+)$. Relief, proximity to the ocean, and latitude (which are determinant of different climatic regimes of rainfall) determine different coherent subregions. If fewer stations were 

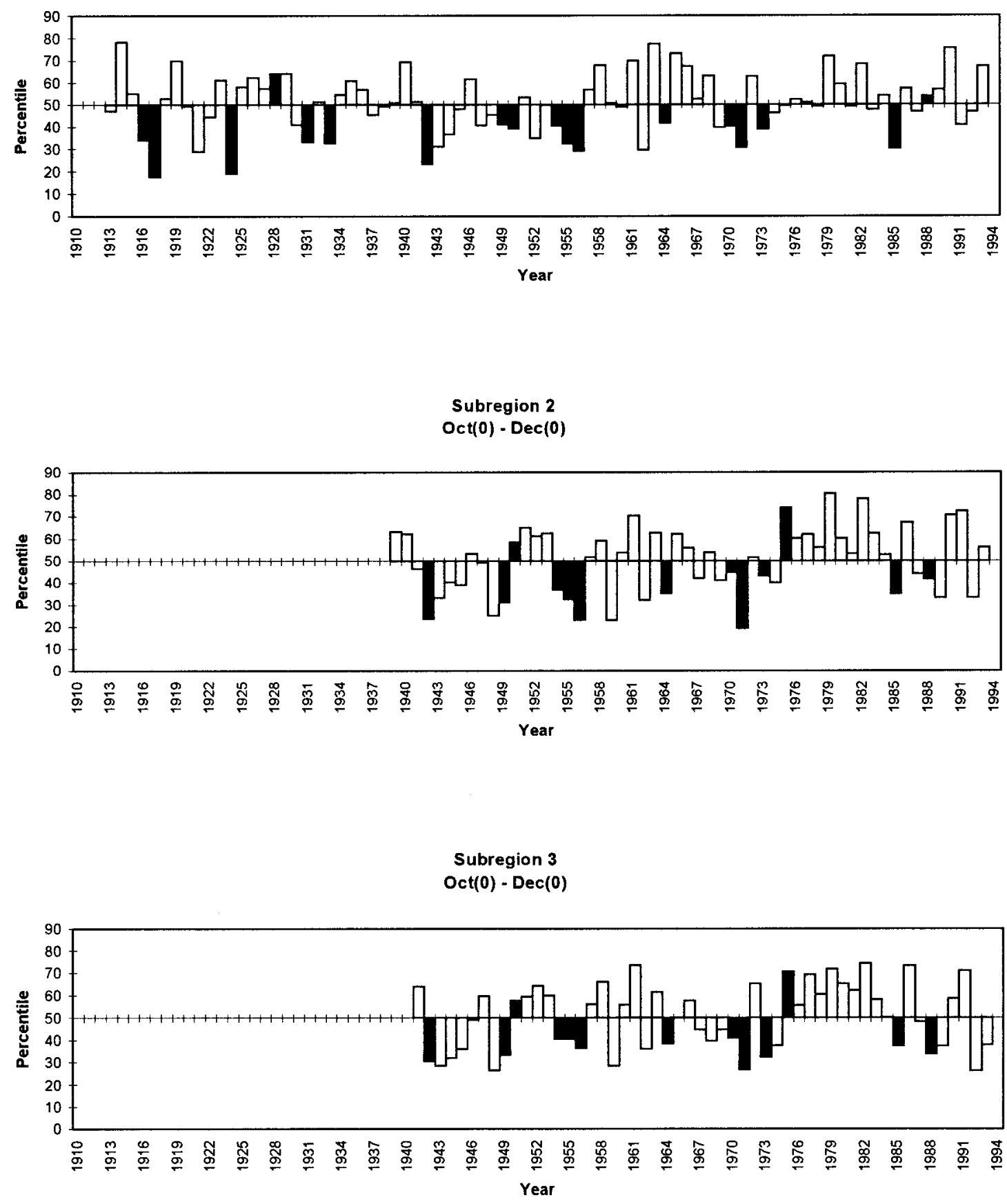

FIG. 11. Time series of station-averaged precipitation percentiles within the indicated subregions for periods in springsummer. The black bars represent La Niña years.

used in southern Brazil, the subregional differences might result in lack of coherence. The spatial coherence of the La Niña-related anomalies is smaller than that of the El Niño-related anomalies when the same 24-month period of analysis is used because there are not consistent anomalies over large areas in the years before and after La Niña events. However, when a shorter period of 12 months is used, the coherence is even larger. Thus, the spatial structure of the La Niña-related anomalies demands a separate analysis in southern Brazil.

2) RH87 concluded that the maximum El Niño-related 


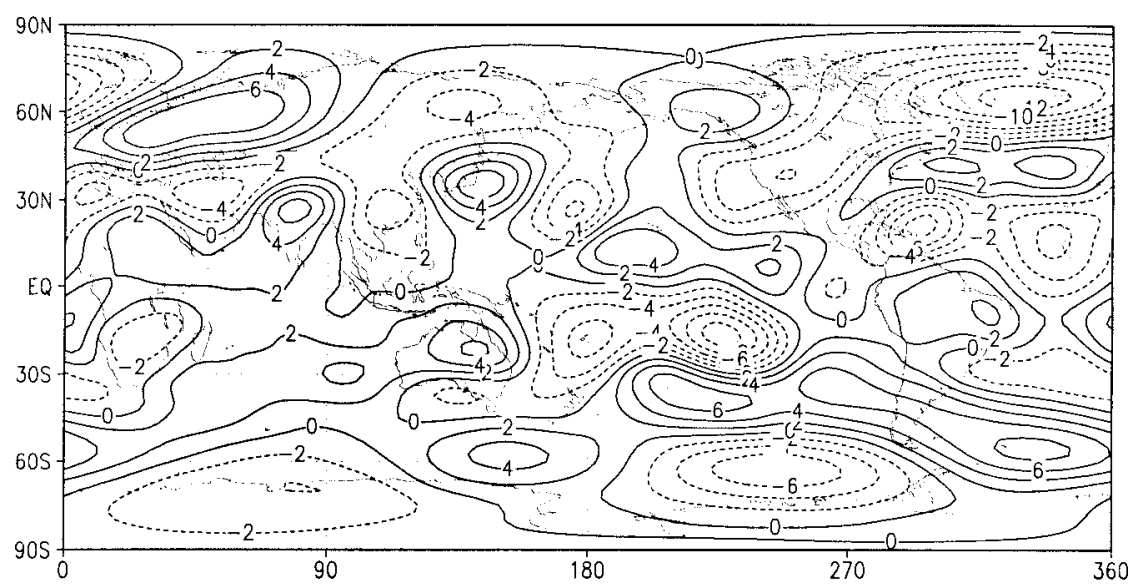

FIG. 12. The 200-hPa streamfunction anomaly composite for November 1979, 1982, and 1986 (contour interval is $2 \times 10^{6} \mathrm{~s}^{-2}$ ).

precipitation anomalies in their core region occur in summer (November, December, January, and February). In southern Brazil they occur in the spring of the El Niño year, with a maximum in $\operatorname{Nov}(0)$. There is a strong weakening and even a reversal of the sign of the anomalies from $\operatorname{Dec}(0)$ to $\operatorname{Jan}(+)$.

3) There are consistent anomalies in the autumn-winter of the year following El Niño all over southern Brazil except in subregion 1 that are not found in RH87's study. These anomalies are associated with some of the worst floods in southern Brazil.

4) Whereas the composite of RH87 shows a consistent high SOI precipitation relationship for the $\operatorname{Jun}(0)-$ $\operatorname{Dec}(0)$ season, the results for southern Brazil show a well-pronounced and consistent dry season from $\operatorname{Sep}(0)$ to $\operatorname{Dec}(0)$ in La Niña events, with a peak in $\operatorname{Nov}(0)$ and a strong decrease of magnitude in $\operatorname{Dec}(0)$. The magnitude of the anomalies is even larger than for El Niño events. There are no consistent precipitation anomalies from $\operatorname{Jun}(0)$ to $\operatorname{Aug}(0)$. As the seasons of most consistent anomalies in El Niño and La Niña years are almost the same, the rainfall response to warm and cold episodes seems to be more linear than the results of RH87 suggest, at least for year (0).

One aspect confirmed by our results relates to the opposition of signals between years (-) and (0) of El Niño and La Niña events, which appears more consistently for El Niño episodes. This is a result of the tendency for warm and cold events to occur in adjacent years and is indicative of the biennial oscillation component in the Southern Oscillation reported, for instance, by Ropelewski et al. (1992) and Tomita and Yasunari (1996). Rainfall anomalies from year (-) until the middle of year (0) of El Niño events tend to be negative, on average, while the anomalies from then on until year $(+)$ tend to be positive. The opposite behavior holds for La Niña events in subregion 1. The sign of the anomalies in years (0) and ( - ) of the composites for opposite types of events is generally coherent, but the same correspondence does not hold for years (0) and $(+)$. This indicates that the appearance of anomalous conditions in the ocean-atmosphere system in year (0) seems to be favored by opposite anomalies in the preceding year. On the other hand, anomalous conditions in year $(0)$ in many instances tend to return toward normal or to persist during year $(+)$ instead of turning to opposite anomalies.

The accurate description of the spatial structure and temporal development of the rainfall anomalies associated with El Niño and La Niña events in southern Brazil allows advancement in the analysis of the connection between these anomalies and the normal annual precipitation cycle. From late winter through late spring of El Niño years there is a progression of the most consistent anomalies from west [subregion 1: $\operatorname{Aug}(0)$ $\operatorname{Dec}(0)$ ] to east [subregion 4: $\operatorname{Oct}(0)-\operatorname{Dec}(0)]$. The same holds for the dry anomalies during La Niña events. This evolution is related to the different rainfall regimes (Fig. $3)$. The peak anomalies occur during $\operatorname{Nov}(0)$ all over southern Brazil. A large part of the wet anomalies in spring of El Niño years is due to the intensification of mesoscale convective complexes in this region. They are common in the western part of southern Brazil (also in northwestern Argentina and southwestern Paraguay) and are responsible for the peak wet season in the spring. Their intensification is probably associated with the strengthening of the subtropical jet over the region during El Niño events. The composite of streamfunction anomalies during the warm events of 1979, 1982, and 1986 (Fig. 12), computed from the National Centers for Environmental Prediction reanalysis data (base period 1979-95), shows that the 200-hPa subtropical westerly winds tend to be stronger than normal. It also discloses an anomalous cyclonic circulation southwest of South America and an anticyclonic anomaly over southeastern 
Brazil, in the subtropics. These features favor baroclinic developments and are conducive to anomalous rainfall over southern Brazil. An approximately reversed situation is revealed by a cold event composite, as can be seen in Fig. 17 of RH89. As suggested by Grimm and Silva Dias (1995) and confirmed by preliminary results reported by Grimm (1996a,b), such circulation anomalies are closely related to SST anomalies in some regions of the eastern Pacific.

The anomalies in the autumn and winter after El Niño, not detected in previous studies, occur over most of southern Brazil except in its northwestern part. They are stronger and more persistent in the southeastern part, where the autumn-winter rainy season is more important. The causes of these consistent anomalies are not clear. It is possible that, besides the Pacific influence, they are also related to anomalous SST in the Atlantic Ocean or to anomalous conditions of the South Atlantic anticyclone at this time.

Although there is a connection between the season of maximum El Niño-related precipitation anomalies and the normal annual precipitation cycle, they are not exactly in phase. A clear example of this behavior is the weakening and even reversal of the wet anomalies of the spring of year (0) in Jan(+) (Fig. 6), in spite of the large area with peak rainy season in summer (December-February and January-March) (Fig. 3). The small impact of El Niño on rainfall in southern Brazil during that period is consistent with the nonsignificant correlation found by Grimm (1996a) between rainfall over part of southern Brazil and SST in the Pacific Ocean for the season December-February. It is possible that local effects combined with large-scale effects would be responsible for the decrease of the monsoonrelated rain peak of midsummer. During El Niño events the strong positive rainfall anomalies during spring and early summer increase the soil moisture and thus the evaporation during summer, decreasing sensible heating. Therefore, monsoonlike circulation leading to higher precipitation would weaken. Besides, during warm events the westerly subtropical zonal circulation is stronger, also contributing to a weaker monsoonlike circulation in southeastern South America. The opposite tendency, though not so clear, is observable during $\mathrm{La}$ Niña events.

The relatively low-frequency forcing associated with El Niño and La Niña events may be translated into a higher-frequency response because of the interaction between the associated large-scale anomalies and the local annual cycle of precipitation (and its mechanisms) as well as land surface processes. Actually it seems that the positive rainfall anomalies due to El Niño occur when circulation anomalies favor the usual rainfall mechanisms in a season. Suppressed rainfall during La Niña occurs when the opposite is true. The rainfall anomalies during spring of El Niño and La Niña events, as well as the reversal of these anomalies in midsummer, are examples of that interaction.

Acknowledgments. CNPq (Brazil) has supported this research. Acknowledgments are due to Simone M.S. da Costa, Pedro G. Ferlizi, and Edmilson D. de Freitas for help in data processing, and thanks to Humberto J. Buzzi for help with the figures. We are grateful to an anonymous reviewer and Pedro L. Silva Dias for their useful comments, and to the International Research Institute for Climate Prediction and the National Oceanic and Atmospheric Administration/Office of Global Programs for additional computational support to this research.

\section{REFERENCES}

Grimm, A. M., 1996a: Sea surface temperatures in the Pacific and rainfall over part of Southern Brazil. Part I: Correlations. Ann. Acad. Bras. Cienc., 68, 3-9.

, 1996b: Sea surface temperatures in the Pacific and rainfall over part of Southern Brazil. Part II: Dynamical mechanisms. Ann. Acad. Bras. Cienc., 68, 11-16.

— interactions with influence functions of a barotropic model. $J$. Atmos. Sci., 52, 3538-3555.

Kiladis, G. N., and H. F. Diaz, 1989: Global climatic anomalies associated with extremes in the Southern Oscillation. J. Climate, 2, 1069-1090.

Quinn, W. H., D. O. Zopf, K. S. Short, and R. T. W. Kuo Yang, 1978: Historical trends and statistics of the Southern Oscillation, El Niño, and Indonesian droughts. Fish. Bull., 76, 663-678.

Rasmusson, E. M., and T. H. Carpenter, 1983: The relationship between eastern equatorial Pacific sea surface temperatures and rainfall over India and Sri Lanka. Mon. Wea. Rev., 111, 517528.

Ropelewski, C. H., and S. Halpert, 1987: Global and regional scale precipitation patterns associated with the El Niño/Southern Oscillation. Mon. Wea. Rev., 115, 1606-1626.

, and - 1989: Precipitation patterns associated with the high index phase of the Southern Oscillation. J. Climate, 2, 268-284. , - _ and X. Wang, 1992: Observed tropospheric biennial variability and its relationship to the Southern Oscillation. J. Climate, $\mathbf{5}, 594-614$.

Schneider, U., and H. E. Fleer, 1989: Development of sea surface temperature, surface wind and divergence anomalies during a composite ENSO episode. Theor. Appl. Climatol., 39, 146-159.

Tabony, R. C., 1983: The estimation of missing climatological data. J. Climatol., 3, 297-314.

Tomita, T., and T. Yasunari, 1996: Role of the northeast winter monsoon on the biennial oscillation of the ENSO/monsoon system. J. Meteor. Soc. Japan, 74, 399-412.

Trenberth, K. E., 1996a: El Niño-Southern Oscillation. Climate Change: Developing Southern Hemisphere Perspectives, T. W. Giambelluca and A. Henderson-Sellers, Eds., John Wiley, 145173.

, 1996b: El Niño definition. CLIVAR-Exchanges, 1, 6-8.

Velasco, I., and J. M. Fritsch, 1987: Mesoscale convective complex in the Americas. J. Geophys. Res., 92, 9591-9613. 